\title{
Czestaw Machelski* \\ Effects of Surrounding Earth on Shell During the Construction of Flexible Bridge Structures
}

https://doi.org/10.2478/sgem-2019-0002

received December 14, 2018; accepted April 18, 2019.

\begin{abstract}
A characteristic feature of soil-steel structures is that, unlike in typical bridges, the backfill and the carriageway pavement with its foundation play a major role in bearing loads. In the soil-steel structure model, one can distinguish two structural subsystems: the shell made of corrugated plates and the backfill with the pavement layers. The interactions between the subsystems are modelled as interfacial interactions, that is, forces normal and tangent to the surface of the shell. This is a static condition of the consistency of mutual interactions between the surrounding earth and the shell, considering that slip can arise at the interface between the subsystems. This paper presents an algorithm for determining the internal forces in the shell on the basis of the unit strains in the corrugated plates, and subsequently, the interfacial interactions. The effects of loads arising during the construction of a soil-steel bridge when, for example, construction machines drive over the structure, are taken into account in the analysis of the internal forces in the shell and in the surrounding earth. During construction, the forces in the shell are usually many times greater than the ones generated by service loads. Thus, the analytical results presented in this paper provide the basis for predicting the behaviour of the soil medium under operational loads.
\end{abstract}

Keywords: Soil-steel structures; effects of surrounding earth on shell; construction phase.

\section{Introduction}

This paper discusses the flexible civil engineering structures, using as an example soil-steel bridge structures. The main feature of the latter is that, unlike in typical bridges, the backfill and the carriageway pavement with its foundation play a major role in bearing loads. ${ }^{[1,2,3]}$ The construction phase, when the thickness of the soil surcharge (the backfill over the shell) is minimal and there is no pavement, is studied in this paper. During backfilling, the shell is subject to considerable strains, since it is a geometrical form restraining the soil in the structure under construction. This means that the shell takes over the earth pressure, similar to a retaining (but flexible) wall. Only when surrounded with backfill, the shell interacting with the soil surcharge becomes an effective structural member, where by the structure can carry considerable external loads, as in Fig. 1. $^{[1,3]}$

The shell made of corrugated plates is highly rigid, but only as a member of the structure embedded in soil (this is the case when the soil-steel structure is in service). As the thickness of the soil surcharge increases, the impact of the imposed loads (in the form of concentrated forces) decreases. Also, the impact of vehicles on the shell is reduced owing to the rigidity of the road pavement/track superstructure. ${ }^{[3]}$

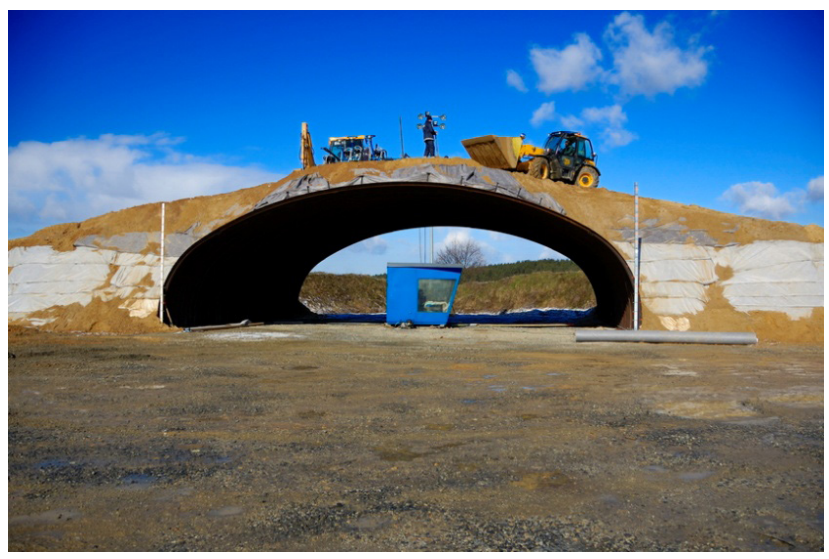

Figure 1: Loads occurring during the construction of soil-steel structure. 


\section{Effects of surrounding earth on soil-steel structure}

In soil-steel structure models, one can distinguish two structural subsystems: ${ }^{[4,8]}$ the backfill plus the pavement with its foundation, and the shell. As a computational model of the soil-steel structure during its service life, a 3D model is used. ${ }^{[1,5,6]}$ For the soil-steel structure during its construction, a simplified model in the form of its circumferential section, that is, a 2D model shown in Fig. 2 , can be assumed. The corrugated steel plate in the soilsteel structure model is represented by a reticular bar structure. ${ }^{[2,7]}$ In the 2D model, it is reduced to a bar in the form of a circular sector.

If unit strains in two points of a corrugation, as in the cross section of the bar shown in Fig. 3, are to be calculated, then using axial forces $n$ and bending moments $m$, one can formulate the following two equations for the corrugation crest: ${ }^{[8]}$

$$
\varepsilon_{g}=\frac{n}{E A}+\frac{m}{E I} v_{g}
$$

and for the corrugation valley:

$$
\varepsilon_{D}=\frac{n}{E A}-\frac{m}{E I} v_{D},
$$

where $\mathrm{v}_{\mathrm{g}}$ and $\mathrm{v}_{\mathrm{D}}$ are the distances of the points from the axis of inertia. In order to determine the unit strains in any shell point, tensometric measurements are performed using the configuration of measuring points, as shown in Fig. 3, located on the plate's surface accessible from the inside. Under the assumption of Bernoulli's principle concerning planar cross sections, using a twin set of strain gauge sensors, one can determine the strains along the axis of inertia of the corrugated plate cross section from the relation: ${ }^{[8]}$

$$
\varepsilon=\frac{n}{E A}
$$

From the difference between the values one gets:

$$
\varepsilon_{g}-\varepsilon_{D}=\frac{m}{E I} f
$$

Formula (4) takes into account that $v_{g}+v_{D}=f$ is the distance between the points, and at the same time, it is the corrugation height.

Unit strains are measured on site using strain gauge sensors glued to the underside (accessible from below) of the corrugated plate. Therefore, the strain in the

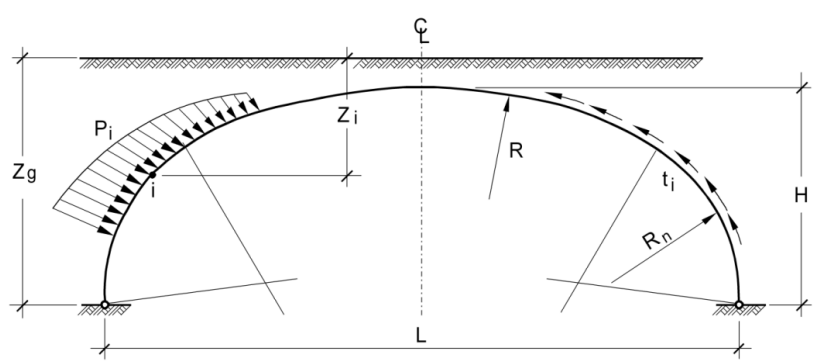

Figure 2: Model of soil-steel structure geometry and interactions.

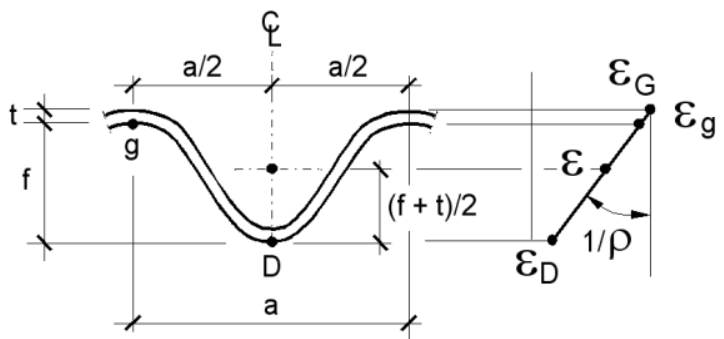

Figure 3: Corrugated plate cross section and distribution of unit strains.

(inaccessible) corrugation crest on the backfill side is calculated as follows:

$$
\varepsilon_{G}=\frac{1}{f}\left[(f+g) \varepsilon_{g}-g \cdot \varepsilon_{D}\right]
$$

Unit strains along the centroidal axis are calculated from the formula:

$$
\varepsilon=\frac{1}{2 f}\left[(f+g) \varepsilon_{g}+(f-g) \varepsilon_{D}\right]
$$

From the unit strain values in the corrugated plate cross section shown in Fig. 3, one gets bar curvature radius $\rho$ and curvature $\kappa$. They are interrelated by the strength dependence given in the formula:

$$
\kappa=\frac{1}{\rho}=\frac{\varepsilon_{g}-\varepsilon_{D}}{f}
$$

The interaction between the structure's subsystems is modelled as interfacial interactions in the form of surface forces, ${ }^{[3]}$ as a rule decomposed into two components: normal $p$ and tangent $t$, as in Fig. 3: 


$$
p(s)=\frac{n}{R}+\frac{d^{2} m}{d s^{2}}=\frac{E A}{R \cdot a} \varepsilon+\frac{E I}{a} \frac{d^{2} \kappa}{d s^{2}}
$$

and

$$
t(s)=\frac{d n}{d s}+\frac{d m}{R \cdot d s}=\frac{E A}{a} \frac{d \varepsilon}{d s}+\frac{E I}{R \cdot a} \frac{d \kappa}{d s}
$$

$E A / a$ and $E I / a$ in formulas (8) and (9) are the rigidities of a shell zone with corrugation length $a$, while $d s$ is a differentially small segment of the perimeter zone of the shell arc. In this paper, the shell's upper part, where the curvature radius amounts to $R$, is analysed. In this part of the shell, the effects generated in the course of the construction and the service life and the effects produced by the moving loads add up.

A measuring setup installed in a selected perimeter zone is used to investigate the internal forces in shells made of corrugated plates. In each measuring point, pairs of strain gauge sensors are installed in the corrugation's crest and valley, as shown in Fig. 3. Usually a regular configuration of measuring points, as shown in Fig. 5, is used to determine the interfacial interactions, whereby differential equations (8) and (9) can be replaced with difference relations. From the dependence between internal static forces $n(s)$ and $m(s)$, expressed as a function relative to the axis (s) running along the perimeter zone of the shell, as in Fig. 4, one gets normal interactions:

$$
p_{j}=\frac{E A}{R} \varepsilon_{j}+\frac{E J}{a \cdot c^{2}}\left(\kappa_{i}-2 \kappa_{j}+\kappa_{k}\right)
$$

and tangent interactions:

$$
t_{i j}=\frac{E A}{a \cdot c}\left(\varepsilon_{i}-\varepsilon_{j}\right)+\frac{E J}{R \cdot a \cdot c}\left(\kappa_{i}-\kappa_{j}\right)
$$

The value of $p_{j}$ is calculated in shell measuring point $j$, while forces $t_{j k}$ are calculated between points $j$ and $k$, as in Fig. 4. The distances between points $i, j, k$ are circular sectors, as in Fig. 4, with arc length $c$. From the geometrical dependences in Fig. 4, it follows that

$$
R=\frac{F^{2}+C^{2}}{2 F}
$$

The interfacial interactions originate from compression and bending. From formulas (10) and (11), one gets a

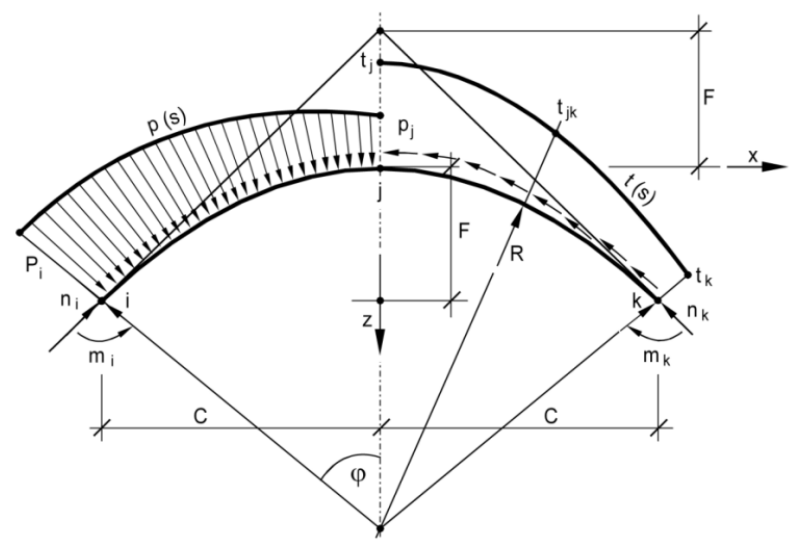

Figure 4: Designations of internal forces and interfacial interactions in segment of perimeter zone of shell.

characteristic parameter, being a dependence between the rigidity and geometry of the perimeter zone, in the form:

$$
K=\frac{E A}{E I} R \cdot f
$$

where $E=205000 \mathrm{MPa}$ is the strength characteristic of the material (steel).

\section{Soil-steel bridge in Ostróda}

In order to illustrate the above computational algorithm, it is applied here to the results of measurements carried out on the motorway soil-steel bridge in Ostróda ${ }^{[8]}$ (Poland). A wildlife migration route and a local road pass under the bridge. Since the bridge carries four roadways, each with two traffic lanes separated by a median strip, its width amounts to $B_{\mathrm{g}}=61.82 \mathrm{~m}$ and $B_{\mathrm{d}}=95.70 \mathrm{~m}$ at respectively the embankment crest and toe. This bridge structure holds a world record for shell $\operatorname{span}^{[8]}$ (the previous record was held by the shell with $L=24 \mathrm{~m}$ built in Canada).

The shells of soil-steel structures are made of corrugated plates. Using circular plate segments, one can make shells having complex cross-sectional shapes. The common geometric feature of such shells as the one shown in Fig. 2 is the circular plate with curvature radius $R=16.632 \mathrm{~m}$ (and corner $R_{\mathrm{n}}=6.12 \mathrm{~m}$ ), situated in the upper part of the crown. The geometric characteristics of the shape of the shell are its span $L=25.724 \mathrm{~m}$ and height $H$ $=9.11 \mathrm{~m}$. The geometry of the shell's corrugated plate is expressed by its technical designation UC $500 \times 237 \times 9.65$ standing for the UltraCor type with parameters: $a=500-$ 
corrugation length, $f=237$ - corrugation height and $g=$ 9.65 - plate thickness. The geometric index of the shell's perimeter zone calculated from formula (13) on the basis of the geometric characteristics of the cross section of the plate: $A / a=14.51 \mathrm{~mm}^{2} / \mathrm{mm}$ and $I / a=96766 \mathrm{~mm}^{4} / \mathrm{mm}$ amounts to:

$$
K=\frac{14.51}{96766} 16632 \cdot 237=591
$$

Figure 5 shows the arrangement of measuring points on the shell. ${ }^{[8]}$ Figure 6 shows plots of interfacial interaction (normal $p$ and tangent $t$ ) components versus backfill thickness $z_{\mathrm{g}}$ (as shown in Fig. 2). In a special case when $\mathrm{z}_{\mathrm{g}}>H$, the thickness of the soil surcharge over the shell amounts to $h=\mathrm{z}_{\mathrm{g}}-H$. The numbers of the shell crown measuring points are marked on the horizontal axis of the diagrams. In this case, value $c=2.02 \mathrm{~m}$ is the distance between the strain gauges in the perimeter zone and the distance between points in the finite difference grid, as in formulas (10) and (11).

The highest values in the diagram of normal forces $p$ (s) occur in the place where curvature radius $R$ changes into $R_{\mathrm{n}}$ (points 1-4 and 15-18). The increase in the values is also due to the greater distance $z_{\mathrm{j}}$, as in Fig. 2. In the middle part of the diagram (i.e., in the crown area), especially when $z_{\mathrm{g}}<H=9.11 \mathrm{~m}$, there is no backfill over the shell. Then the interactions should be reduced to minimum: $p \approx$ 0 and $t \approx 0$ (consistently with the assumptions). Therefore, the very low values of $p$ and $t$ can be treated as due to the inaccuracy of the strain gauge readings.

Tangent forces $t(\mathrm{~s})$ are directed consistently with increasing in Fig. 4. Thus, the tangent forces usually assume positive values for points 1-9 and negative values for points $9-17$. In the middle part of the diagram (i.e., in the crown area), the low values of $t$ are for no backfill over the shell. When $p$ and $t$ are compared, it appears that, unlike forces $p$, the tangent forces show no tendency to increase with backfill thickness $z_{\mathrm{g}}$. The asymmetry of interactions $p$ and tangent forces $t$ is normal, indicating backfill laying and compacting non uniformity. This is also observed when conducting the surveying measurements of shell deformations. The zone in which the curvature radius changes from $R$ to $R_{\mathrm{n}}$ and the shell support segment are not included in the diagrams, since the results there are disturbed due to the complex mode of support (intermediate between pin and fixed support). ${ }^{[9]}$

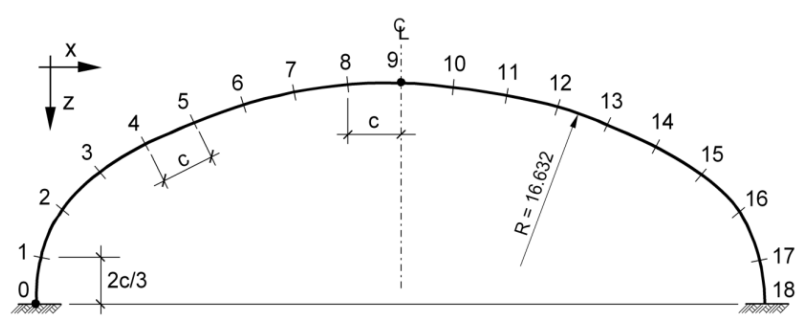

Figure 5: Arrangement of measuring points in perimeter zone of shell in Ostróda.
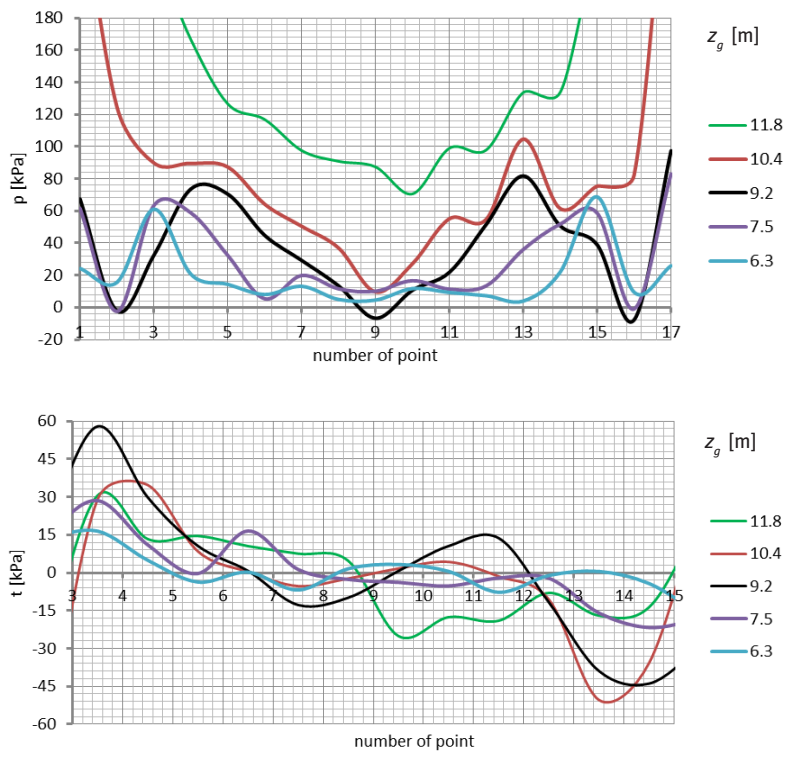

Figure 6: Plots of interfacial interactions along perimeter zone of shell.

\section{Test soil-steel bridge in Rydzyna}

The results of measurements carried out on the soil-steel bridge in Rydzyna ${ }^{[3,9]}$ by means of electrical resistance strain gauges are presented here as an example. ${ }^{[3]}$ The structure has a record span of $17.594 \mathrm{~m}$ and its shell is made of SC $381 \times 140 \times 7$ plates without cover plates. The geometric parameters of the shell's perimeter zone, relative to the axis of inertia of the corrugated plates, are: shell height $H=5.459 \mathrm{~m}$ and in-crown curvature radius $R$ $=13.735 \mathrm{~m}$. The geometric characteristics of the plate cross section are: $A / a=9.81 \mathrm{~mm}^{2} / \mathrm{mm}$ and $I / a=24165 \mathrm{~mm}^{4} /$ $\mathrm{mm}$. The value of the general characteristic of this shell is similar to that calculated for the Ostróda soil-steel bridge, amounting to: 


$$
K=\frac{9.81}{24165} 13735 \cdot 140=781
$$

The measuring setup is shown in Fig. 7. The distance between the points close to the crown amounts to $c=1.202$ $\mathrm{m}$. The length of the segment adjacent to the crown is $c \Delta=$ $1.202 \times 2.88=3.462 \mathrm{~m}$. When the arrangement of measuring points is irregular, the derivative of the curvature from formula (10) is calculated from the equation:

$$
\frac{d^{2} \kappa}{d s^{2}}=\frac{2}{c^{2}(1+\Delta) \Delta}\left[\Delta \cdot \kappa_{i}-(1+\Delta) \kappa_{j}+\kappa_{k}\right]
$$

where $\Delta=3.462 / 1.202=2.88$.

Figure 8 shows the changes in normal components $p$ and tangent components $t$ of the interfacial interactions. The values of $z_{g}$ (soil surcharge thickness) are marked on the horizontal axis of the diagram while the numbers of the considered points are given in the legend. On the basis of the ordinates of the graphs, one can calculate soil surcharge thickness as $h=z_{\mathrm{g}}-5.46 \mathrm{~m}(H=5.459 \mathrm{~m})$. It appears from the $p\left(\mathrm{z}_{\mathrm{g}}\right)$ plots that the interactions increase almost linearly up to $z_{\mathrm{g}}=6.6 \mathrm{~m}$.

$$
p_{(h=1.2)}=\frac{30.4-2.4}{6.6-5.4} h=23.3 \cdot h[\mathrm{kPa}]
$$

The value of $23.3\left[\mathrm{kN} / \mathrm{m}^{3}\right]$ is close to the bulk density of the backfill soil. When $h>1.1 \mathrm{~m}\left(\mathrm{z}_{\mathrm{g}}>6.6 \mathrm{~m}\right), p$ does not increase, which can be ascribed to arching. Functions $p$ (s) for points 4 and 6 adjacent to the crown are very similar. Obviously, the pressures in the crown are relatively weaker because of the smaller soil surcharge thickness.

\section{Dismantling Rydzyna bridge soil surcharge}

A process reverse to the construction of the soil-steel structure - the dismantling of the structure - is analysed here. ${ }^{[3,9]}$ The dismantling was carried out after 8 years of the existence of the structure without being in service. The dismantling consisted in removing successive 0.3 $\mathrm{m}$ thick backfill layers (similar to the ones laid during construction). Thus, the soil surcharge thickness, defined by $z_{g}$ (as for the construction phase) is decreased in the successive dismantling phases. Consequently, interaction $p\left(z_{g}\right)$ is reversed, that is, the final earth pressure is reduced.

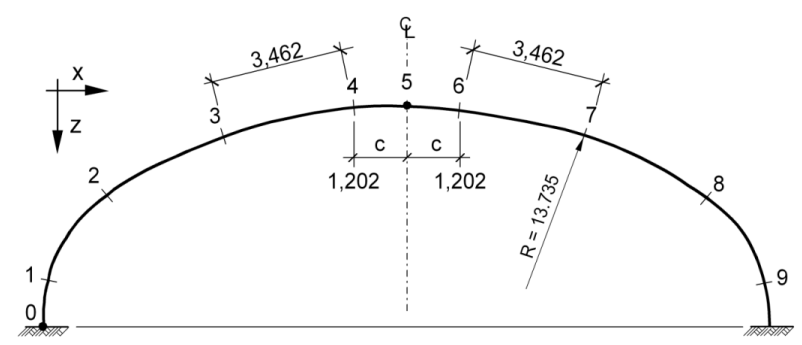

Figure 7: Arrangement of measuring points in perimeter zone of shell in Rydzyna.

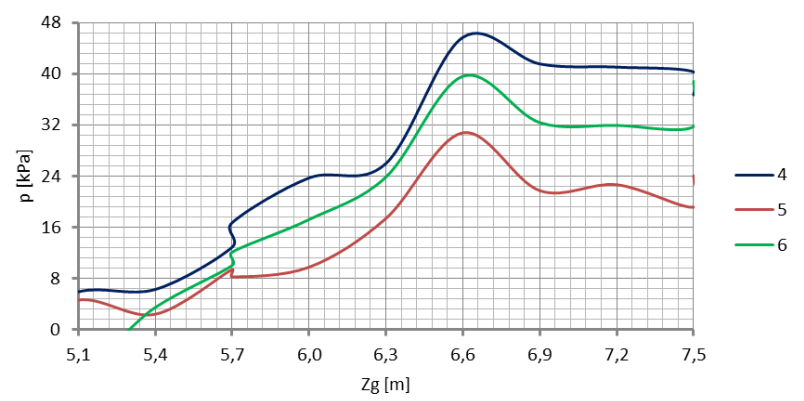

Figure 8: Plots of normal interactions along perimeter zone of shell.

In this case, the pressure is reduced to $p \approx 0$ when soil surcharge thickness approaches zero.

Figure 9 shows the results of similar measurements as the ones performed during the construction of the soil-steel structure, using the same measuring setup as shown in Fig. 7. Two places in which $p$ changes sharply at the same value of $z_{\mathrm{g}}$ are visible in the graphs. They correspond to a work break lasting about 15 hours when $z_{\mathrm{g}}=6 \mathrm{~m}$ and $z_{\mathrm{g}}=6.6 \mathrm{~m}$. At $z_{\mathrm{g}}=6.6 \mathrm{~m}$, the structure was tested using the loader shown in Fig. $1{ }^{[3]}$ At that time, the soil surcharge layer amounted to $h=1.2 \mathrm{~m}$. The loads resulted in the sharp changes in pressure, shown in Fig. 10, during the primary and secondary (return) travel of the loader over the structure. The location of the vehicle on the structure is defined by the position of its front axle $x_{\mathrm{p}}$ (when $x_{\mathrm{p}}=0$, the axle is situated over the shell crown). The pressures change as a result of the vehicle travel, which was presented as the functions $p(\mathrm{~s})$ and $t(\mathrm{~s})$ in [3]. The reduction of $p(\mathrm{~s})$ to its initial value indicates a hysteresis loop. ${ }^{[2,10]}$ However, in many cases, residual displacements arise. Therefore, the plots of the pressure changing during the travel of the loader supplement the graphs presented in Fig. 9.

The results presented in figures 8 and 9 can be directly compared. Such a comparison shows a considerable decrease in pressure at the beginning of dismantling 


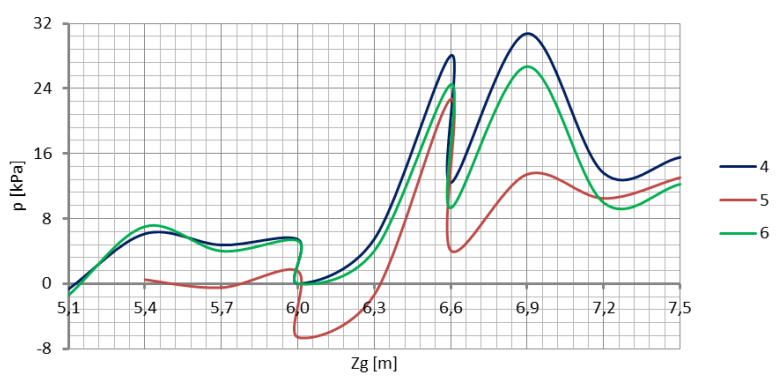

Figure 9: Plots of interfacial interactions along perimeter zone of shell.

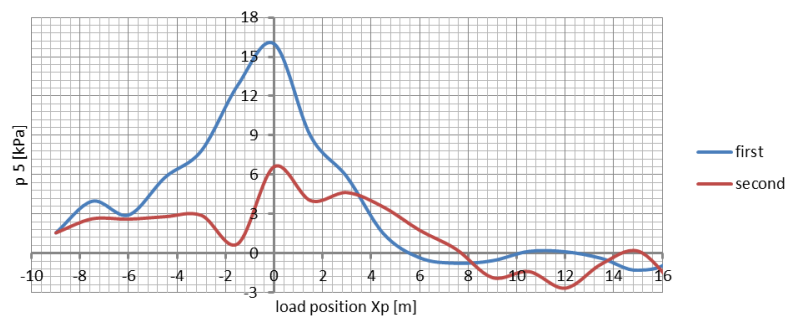

Figure 10: Normal interactions during loader travel over soil-steel structure in Rydzyna.

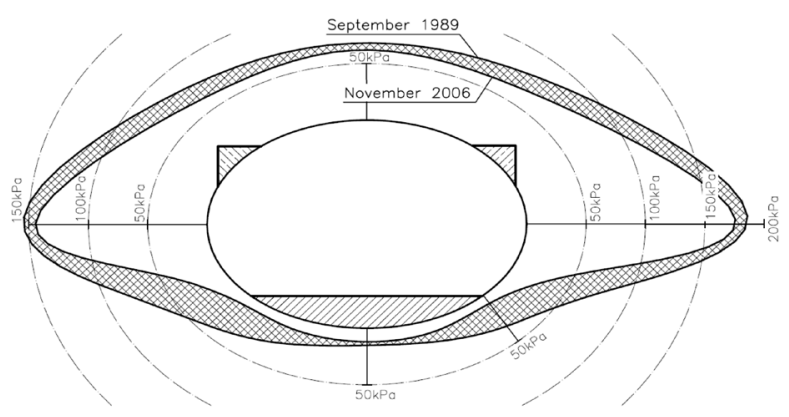

Figure 11: Changes in normal interactions in the course of service life of soil-steel structure [11].

$\left(z_{g}=5.5 \mathrm{~m}\right)$ relative to the end of construction $\left(z_{g}=7.5 \mathrm{~m}-\right.$ Fig. 7). Changes in earth pressure in soil-steel structures are something natural. ${ }^{[1]]}$ Figure 10 shows a reduction in the earth pressures exerted on the shell after 17 years of service life of the bridge. The changes in earth pressure were measured directly using earth pressure cell.

\section{Conclusion}

The algorithm presented in this paper is used to convert the results of tensometric measurements performed on the corrugation's crest and in its valley into the soil-shell interfacial interactions. The analytical results obtained in this way apply to the shell's upper part in which the effects of operational loads and construction loads add up. The analyses carried out in this paper are limited to soil-steel bridges during their construction, that is, when they have no pavement. The pavement constitutes a major structural layer of such bridges when they are in service. Investigations of soil-steel structures typically focus on the interactions normal to the surface of the shell, which are determined on the basis of direct measurements performed using earth pressure cells. The advantage of the proposed algorithm is that one can estimate the tangent (friction) forces between the ground and the shell. Interactions $t(\mathrm{~s})$ are difficult to determine on the basis of measurement results. The presented analyses show that forces $t(\mathrm{~s})$ undergo reduction as the successive layers of backfill are laid, whereas forces $p(\mathrm{~s})$ increase.

In the analyses, attention is drawn to the changes in earth pressure after a construction vehicle (e.g., a loader) drives on the soil surcharge, that is, to the changes caused by construction loads. It is noted that the earth pressures arising during the primary travel differ considerably from the ones arising during the secondary (return) travel of the vehicle. This was observed earlier when measuring the displacements of the shells in soil-steel structures. ${ }^{[2,3,8]}$

A major component of soil-steel structures is backfill. Changes in its physical characteristics contribute to a reduction in interfacial interactions, as observed during the on-site investigations of earth pressures exerted on the shell. The behaviour of the backfill is also affected by changes in the moisture content of the soil. ${ }^{[12]}$

\section{References}

[1] Machelski C. (2015) Stiffness of railway soil-steel structures. Studia Geotechnika et Mechanica. 4, 29-36.

[2] Sobótka M. (2014) Numerical simulation of hysteretic live load effect in soil-steel bridge. Studia Geotechnika et Mechanica. 36.1. 103-109.

[3] Machelski C. (2018) Budowlane obciążenia podatnych obiektów inżynierskich. Construction load of the soil-steel structures. Przegląd Komunikacyjny 10, 30-35.

[4] Machelski C, Janusz L. (2017) Application of Results of Test in Developing 2D Model for Soil-Steel Railway Bridges. Journal of the Transportation Research Board. Solid Mechanic, 1, 70-75.

[5] Asp 0., Laaksonen A. (2017) Instrumentation and FE-analysis of a large span culvert built under railway. Structural Engineering International. Vol. 26, No 4, 357-364.

[6] Moore J.D., Regier C., Hoult N.A. (2017) Surface load testing of new circular and elliptical metal culverts at shallow cover. Archives of Institute of Civil Engineering 23, 219-227. 
[7] Szajna W.S. (2007) Numerical model for the analysis of construction process of soil-steel culverts. Archives of Institute of Civil Engineering. 1, 215-223.

[8] Machelski C. (2018) Soil-steel structure shell displacement functions based on tensometric measurements. Studia Geotechnika et Mechanica. 4, 29-36.

[9] Tomala P., Nowak M., Samolewski W., Szyszka M. (2019) SoilSteel Composite Structure Monitoring During Bacfilling and Uncovering - Observations and Remarks. Conf. Transportation Research Board of Nationals Academies, Washington D.C., 12-15 January, 2019.

[10] Sielver M. L., Seed H. B. (1971) Volume Changes in Sands during Cyclic Loading. ASCE Soil Mechanics and Foundations Division Vol. 97, No SM9, September 1971.

[11] Vaslestad J., Kunecki B., Johanson T. H. (2007) Twenty one years pressure measurements on buried flexible steel structure. Archives of Institute of Civil Engineering. 1, 233-244.

[12] Łydżba D., Różański A., Sobótka M., Stefaniuk D., Chudy G., Wróblewski T. (2017) Mechanical behaviour of soil-steel structure subjected to live load and different water conditions. Archives of Institute of Civil Engineering. 23, 163-174. 